\title{
CENÁRIO DA BOMBA-RELÓGIO E A RELATIVIZAÇÃO DA PROIBIÇÃO DA TORTURA
}

SCENARIO OF THE PUMP-WATCH AND THE RELATIVIZATION OF THE BAN OF TORTURE

André Luiz Pereira SPINIELI ${ }^{1}$

ISSUE DOI: $10.21207 / 1983.4225 .442$

\section{RESUMO}

Este artigo procurou investigar a incidência da, recentemente desenvolvida, teoria do cenário da bomba-relógio no Direito Penal e, sobretudo, no tocante à constitucionalidade do objeto principal da tese: a relativização da proibição da tortura. $\mathrm{O}$ propósito do trabalho é demonstrar o enorme risco de se adotar um pressuposto como tal para obter confissões de uma pessoa humana. Em primeiro lugar, atevese a explicitar os conceitos de direitos humanos, dignidade da pessoa humana e tortura, com a respectiva previsão na ordem constitucional brasileira e o papel dos direitos fundamentais sob esse prisma. Na sequência, ocupou-se de relacionar a ideia aos institutos próprios de Direito Penal. Por fim, cuidou-se da periculosidade da legitimação de atos de cunho cruel. No trâmite do trabalho, recorreu-se a tratados internacionais, casos hipotéticos, os quais tiveram a tortura como peça-chave, bem como a atenção dada por doutrinadores estrangeiros ao tema.

\footnotetext{
${ }^{1}$ Graduando em Direito, Faculdade de Direito de Franca (FDF), a concluir em 2018. Graduado em Inglês, Wizard Franca. E-mail: spinieliandre@ gmail.com
} 
Palavras-chave: Direito Penal. Proibição da Tortura. Relativização. Direitos Fundamentais. Cenário da Bomba-Relógio.

\section{INTRODUÇÃO}

O cerne deste artigo é a acepção da teoria do cenário da bombarelógio e sua perigosa adoção, seja no Brasil, nos Estados Unidos, berço do tema, ou qualquer outra nação adotante do Estado Democrático de Direito.

A proposição age, em uma situação imaginada, como manipulador das reações do torturador em relação à vítima e vice-versa. O tema ganhou força pela atual sistemática jurídico-política que o planeta vive.

O motivo do presente trabalho, bem como sua delimitação, é fruto da necessidade de análise do efeito causado pelo "cenário da bombarelógio", que cria dúvidas quanto a proibição absoluta da tortura em determinados casos. Dúvida esta que leva o público a aceitar, diante de uma situação que desafia a ética e a justiça, que se crie uma exceção para a vedação da tortura, ou, pelo menos, aceitar que leis anti-tortura não incidam sobre casos extremos.

Outro motivo é a recente promulgação da Lei no $13.260 / 16$, apelidada de "Lei Antiterrorismo", já que a ficção tem sido utilizada pelos adeptos da corrente contrária ao absolutismo na proibição da tortura para parecer aceitável sua aplicação em réus envolvidos em atos terroristas, estendendo da mesma maneira àqueles que ordenam, autorizam ou consintam com a tortura.

A essência da pesquisa foi tecer um posicionamento contrário à admissão da teoria no direito, relatando as ameaças disto.

\section{DIREITOS HUMANOS}

A concepção de que os grupos humanos podem ser sintetizados a um único conceito é, conforme Fábio Konder Comparato, de elaboração recente na trajetória humana. ${ }^{2}$

\footnotetext{
${ }^{2}$ COMPARATO, Fábio Konder. A afirmação histórica dos direitos humanos. São Paulo:
} Saraiva, 2003. p. 7 
Porém, o reconhecimento dos ditos direitos universais, comunitário a qualquer ser do gênero humano, é de origem greco-romana, quando Marco Túlio Cícero apresentou a tese da existência de um direito natural regente da vida familiar e da vida pública, que abrangia as relações entre cidadãos - assim chamados aqueles que eram homens livres - e estrangeiros. Tal necessidade de reunião humana era bem sintetizada por sua frase "Dizer que se devem respeitar os concidadãos, mas não os estrangeiros, é destruir a sociedade comum do gênero humano", abreviada pela premissa communis humani generis societas ${ }^{3}$.

Tanto o senso comum quanto a doutrina encontram dificuldades para conceituar o que se entende por direitos humanos. Muitas vezes as respostas são supérfluas ou não abrangem o suficiente para abarcar necessariamente a importância dos direitos previstos em documentos nacionais e internacionais.

Entretanto, seguindo a doutrina brasileira majoritária, os direitos humanos são o aglomerado de direitos considerados indispensáveis para a coexistência humana, pautadano lema ativista francês da liberdade, igualdade e fraternidade, além do acréscimo do respeito à dignidade humana como vetor. São, em suma, na opinião de André de Carvalho Ramos, os direitos essenciais e indispensáveis à vida digna. Atenta ainda que não há um rol pré-estabelecido de tais direitos, pois as necessidades humanas variam de acordo com o contexto histórico e com as novas demandas sociais ${ }^{4}$.

Mostra-se interessante a noção de Louis Henkin, que afirma serem "aqueles concebidos de forma a incluir reivindicações morais e políticas que, no consenso contemporâneo, todo ser humano tem ou deve ter perante sua sociedade ou governo". 5

\section{$1.1 \quad$ DIGNIDADE DA PESSOA HUMANA}

O filósofo alemão Immanuel Kant (1724 - 1804) determinava que

\footnotetext{
${ }^{3}$ RAMOS, André de Carvalho. Teoria geral dos direitos humanos na ordem internacional.São Paulo: Saraiva, 2012. p. 7.

${ }^{4}$ RAMOS, André de Carvalho. Curso de direitos humanos. São Paulo: Saraiva, 2016. p. 24.

${ }^{5}$ HENKIN, Louis. The rights of the man today. New York: Columbia University Press. 1988. p. 1-3.
} 
no reino dos fins tudo tem um preço ou uma dignidade. Quando uma coisa tem um preço, pode-se pôr em vez dela qualquer outra como equivalente; mas quando uma coisa está acima de todo o preço, e, portanto, não permite equivalente, então tem ela dignidade. ${ }^{6}$

A dignidade da pessoa humana, tomando por base a filosofia kantiana, é uma qualidade intrínseca e distintiva presente em cada um dos seres humanos, que é um fim em si mesmo, com direito de autodeterminação, não sendo instrumento para a obtenção de resultados, tampouco possuindo preço, como as coisas. A dignidade é inerente à condição humana, não importando qualquer outro parâmetro distintivo, como credo religioso, paixões políticas ou nacionalidade.

É, conforme André de Carvalho Ramos, um conceito polissêmico e aberto, que está em constante processo de desenvolvimento e construção. ${ }^{7}$

A Constituição Federal de 1988 foi responsável por criar, topograficamente no início, um Título específico que reúne as três gerações de direitos humanos, acompanhando o método de Karel Vasak.

Entretanto, é de destaque a constitucionalização da dignidade da pessoa humana, colocada no texto como um dos fundamentos da República brasileira, pois é incidente sobre todos os demais direitos infraconstitucionais e, até mesmo, os fundamentais.

Trata-se, nos dizeres de alguns doutrinadores, de um postulado axiológico central, que serve como baliza para a utilização e orientação dos aplicadores do Direito, guiando as atividades públicas (eficácia vertical dos direitos fundamentais) e privadas (eficácia horizontal dos direitos fundamentais).

No âmbito internacional, o documento firmado na ONU, em 1948 - a Declaração Universal dos Direitos Humanos - estabelece no seu preâmbulo a indispensabilidade da proteção da dignidade humana por meio do rol de direitos ali elencados. Nas Américas, o Pacto de São José da Costa Rica, de 1969, exige respeito à dignidade inerente ao homem.

O jurista André de Carvalho Ramos defende a existência de dois elementos característicos do princípio da dignidade humana, vejamos: o primeiro é o elemento positivo, que trata a dignidade como defesa da

\footnotetext{
${ }^{6}$ KANT, Immanuel. Metafísica dos Costumes. Lisboa: Edições 70 LDA. 2007. p. 77.

${ }^{7}$ RAMOS, André de Carvalho. Curso de direitos humanos. São Paulo: Saraiva, 2016. p. 69.
} 
existência de condições materiais mínimas para a sobrevivência do ser humano, servindo como piso vital mínimo; e o segundo é o negativo, que consiste na vedação de se impor qualquer tipo de tratamento ofensivo, degradante ou discriminatório. O último, conforme o autor, se amolda ao exemplo da proibição da tortura ou tratamento desumano ou degradante. ${ }^{8}$

\subsection{DIREITO FUNDAMENTAL DA PROIBIÇÃO DA TORTURA}

$\mathrm{O}$ ato da tortura visando à obtenção de informações, bem como para qualquer fim, é altamente repudiada pela comunidade internacional, além de ser considerada uma grave afronta aos direitos humanos, à dignidade da pessoa humana e à integridade pessoal. Diversos são os textos convencionados em âmbito global que tratam do tema.

A título exemplificativo vale citar a Declaração Universal dos Direitos Humanos (art. $5^{\circ}$ ), a Convenção Interamericana para Prevenir e Punir a Tortura (em todo o texto), o Pacto Internacional dos Direitos Civis e Políticos $\left(\operatorname{art.} 7^{\circ}\right)$ e outros, para os quais a proibição tem caráter de jus cogens. Porém, o mais importante documento é a Convenção de Nova Iorque, de 1984, celebrada no domínio da ONU, de onde é possível retirar o conceito de tortura, no art. $1^{\circ}$, como sendo

qualquer ato pelo qual dores ou sofrimentos agudos, físicos ou mentais, são infligidos intencionalmente a uma pessoa a fim de obter, dela ou de uma terceira pessoa, informações ou confissões; de castigá-la por ato que ela ou uma terceira pessoa tenha cometido, ou seja, suspeita de ter cometido; de intimidar ou coagir esta pessoa ou outras pessoas; ou por qualquer motivo baseado em discriminação de qualquer natureza; quando tais dores ou sofrimentos são infligidos por um funcionário público ou outra pessoa no exercício de funções públicas, ou por sua instigação, ou com o seu consentimento ou aquiescência. 
Igualmente, o Direito brasileiro, com fundamento no art. $5^{\circ}$, da Constituição Federal, trata amplamente da proibição da tortura, estabelecendo os seguintes incisos, entre outros:

III - ninguém será submetido à tortura nem a tratamento desumano ou degradante;

XLIII - a lei considerará crimes inafiançáveis e insuscetíveis de graça ou anistia a prática da tortura, o tráfico ilícito de entorpecentes e drogas afins, o terrorismo e os definidos como crimes hediondos, por eles respondendo os mandantes, os executores e os que, podendo evitá-los, se omitirem.

Apesar da vedação da tortura e dos tratamentos desumanos e degradantes, escrito como crime inafiançável e insuscetível de instrumentos extintivos da punibilidade, o ordenamento jurídico brasileiro não tipificou a conduta criminosa tampouco chegou a defini-la. Contudo, esse ato ocorreu em 7 de abril de 1997, por intermédio da Lei $\mathrm{n}^{\circ}$ 9.455, que empregou as seguintes palavras no artigo inaugural:

Art. $1^{\circ}$. Constitui crime de tortura:

I - constranger alguém com o emprego de violência ou grave ameaça, causando-lhe sofrimento físico ou mental:

a) com o fim de obter informação, declaração ou confissão da vítima ou de terceira pessoa;

b) para provocar ação ou omissão de natureza criminosa;

c) em razão de discriminação racial ou religiosa;

II - submeter alguém, sob sua guarda, poder ou autoridade, com emprego de violência ou grave ameaça, a intenso sofrimento físico ou mental, como forma de aplicar castigo pessoal ou medida de caráter preventivo.

Pena - reclusão, de 2 (dois) a 8 (oito) anos. 
$\S 1^{\circ}$ - Na mesma pena incorre quem submete pessoa presa ou sujeita a medida de segurança, a sofrimento físico ou mental, por intermédio da prática de ato não previsto em lei ou não resultante de medida legal.

Merece destaque especial o $\S 1^{\circ}$, que tipifica a conduta de tortura conforme o teor do art. 5', XLVII, alíneas "c" e "e", que veda toda e qualquer pena cruel ao preso ou sujeito punido com medida de segurança.

Luís Greco critica veemente o que se entende por tortura. Diz que, apesar de amplamente aceita, a definição presente na Convenção AntiTortura da ONU é bastante problemática. Aponta que o primeiro defeito é o que vem a ser, de fato, o conteúdo da expressão "dor ou sofrimento", que fica retida numa perspectiva psicológico-naturalista. Defende ainda que o melhor conceito adotado é o da Convenção Interamericana para Prevenir e Punir a Tortura, de 1985. Exemplifica nos seguintes termos:

Se formos conseqüentes, teremos de afirmar a tortura no caso de alguém que raspa a cabeça de uma modelo que faz fotos para shampoo, causando sofrimentos psíquicos enormes, ao mesmo tempo em que teremos que negar a tortura no caso em que alguém chicoteie o crente disposto ao martírio ou o masoquista. ${ }^{9}$

Como se configura, o aspecto primordial da tortura não é a imposição de dor ou sofrimento, mas o exercício de domínio mais completo e irresistível existente sobre uma pessoa, tendo em mente que o torturado se encontra à mercê do Estado, ou seja, em sua esfera de proteção ou guarda.

Há, nos dizeres do autor, uma "perversidade da tortura" na inversão das formulações tradicionais de ação, consentimento e responsabilidade que $\mathrm{o}$ ato da tortura provoca.

Em segundo lugar, outro defeito é no que consiste exatamente a violação da dignidade humana pela tortura, defendendo que só seria possível resolver essa questão se a mera ameaça de imposição de dor física já

\footnotetext{
${ }^{9}$ GRECO, Luís. As regras por trás da exceção - Reflexões sobre a tortura nos chamados “casos de bomba-relógio". Revista Jurídica v. 23, n. 7 (2009). Disponível em: <http://revista.unicuritiba.edu.br/index.php/RevJur/article/view/95>. Acessado em: 10 dezembro 2016.
} 
representasse a tortura, de modo que ameaça de dor e a efetiva imposição desta se igualariam em seu efeito de exclusão da vontade do torturado.

A tortura, de qualquer forma, é crime sob a égide do direito internacional, de observância obrigatória a todos os Estados, havendo pleno consenso entre estes de que todo agente torturador deverá ser submetido à justiça a qualquer tempo, pouco importando o lugar do mundo onde for capturado. ${ }^{10}$

Nestes termos, fica clara a repulsão do Estado brasileiro em relação a qualquer prática de atos de tortura ou a ela equiparados. Defende André Luís Callegari que a estrutura jurídica brasileira comporta diversos dispositivos normativos elaborados com o único fim de combater e erradicar a tortura, que, nas palavras de Augusto Silva Dias:

A proibição da tortura é entre nós absoluta e sem reservas. Em abono do carácter absoluto da proibição, a doutrina argumenta que ela forma o "núcleo de protecção absoluta do direito fundamental 'a integridade pessoal”; que constitui um "arquétipo jurídico", uma regra emblemática de um amplo compromisso para diferenciar claramente o Direito da brutalidade; que pertence ao "indisponível de uma ordem jurídico, ao seu núcleo intocável: 'a cultura dominante". Funcionando como um "tabu jurídico"; ou, como prefere dizer Claus Roxin, que se trata de uma Grundnorm ${ }^{11}$.

Durante as décadas finais do século XIX, Georg Jellinek (1851 1911) criava a teoria dos quatro status dos direitos fundamentais, cujo escopo era classificar, conforme a natureza, a posição do indivíduo face ao Estado.

Robert Alexy, conterrâneo do primeiro jusfilósofo, assevera que a tese é de extrema importância, pois revela posições jurídicas abstratas, com suas palavras, que o Estado se localiza em referência ao indivíduo,

\footnotetext{
${ }^{10}$ Association for the Prevention of Torture. Defusing the Ticking Bomb Scenario: Why we must say No to torture, always. 2007. Disponível em: <http://www.apt.ch/content/files_res/tickingbombscenario.pdf $>$. Acessado em: 6 dezembro 2016.

${ }^{11}$ SILVA DIAS, Augusto. Torturando o inimigo ou libertando da garrafa o génio do mal? Sobre a tortura em tempos de terror, apud CALLEGARI, André Luís. A exclusão da ilicitude do torturador de terceiro possuidor de informação num cenário de tickin time bomb. Disponível em: 〈http://ebooks.pucrs.br/edipucrs/anais/cienciascriminais/III/5.pdf>. Acessado em: 06 dezembro 2016.
} 
permitindo que se compreenda a forma de efetivação e exigência dos direitos fundamentais. ${ }^{12}$

Para o intuito do presente trabalho, o exame recairá apenas sobre a primeira condição, pois é nela que se encontra o princípio-chave em observação: denominado de status passivo (status subjectionis), é onde o indivíduo se encontra em situação de subordinação quanto ao Estado, que conserva atribuições e prerrogativas aptas a vincular o indivíduo ao cumprimento de acertadas condutas, bem como impor limitações, proibições, para as suas ações. São deveres da pessoa humana que são, na verdade, um contributo para a consecução do bem comum.

A verificação dos comentários acerca da teoria de Jellinek permite concluir que a previsão constitucional da proibição absoluta da tortura (art. $\left.5^{\circ}, \mathrm{III}\right)$, existente desde Cartas anteriores à de 1988, como o é nas constituições modernas das sociedades democráticas, é uma situação de passividade do sujeito em relação ao Estado, já que aquele deve cumprir o entrave posto em suas ações, dificultando, ou até mesmo impossibilitando uma impensada minoração.

Por fim, vale lembrar-se de Cesare Bonesana, o Marquês de Beccaria, escreve o clássico livrete condenatório das penas cruéis, ainda em 1764 - período em que se admitia a prática da tortura como punição pelos sistemas legais -, para descrever o quão aterrorizante é essa forma de terror, pelo qual, diz ele, "se exige que um homem seja ao mesmo tempo acusador e acusado", enquanto a "dor se torna o cadinho da verdade, como se o critério desta residisse nos músculos e na fibra de um miserável". ${ }^{13}$

O constitucionalista José Afonso da Silva completa dizendo que a tortura não é só um crime contra a vida, mas "uma crueldade que atinge a pessoa em todas as suas dimensões, e a humanidade como um todo". ${ }^{14}$

\section{TEORIA DO CENÁRIO DA BOMBA-RELÓGIO}

Apresentada pela primeira vez na obra Les Centurions, escrita em 1960 pelo jornalista e ex-soldado francês Jean Lartéguy, que narra os

\footnotetext{
12 ALEXY, Robert. Teoria dos Direitos Fundamentais. São Paulo: Malheiros, 2008. p. 254.

${ }^{13}$ BECCARIA, Cesare. Dei deliti e delle pene. p. 212, apud SILVA, José Afonso da. Curso de Direito Constitucional Positivo. São Paulo: Malheiros, 2008. p. 204.

${ }^{14}$ Idem.
} 
episódios vividos por um batalhão na Guerra da Indochina, da Argélia e de Suez, a teoria se desenvolve quando a personagem principal, o Capitão Julien Boisfeuras, descobre um plano iminente de explosão de bombas em massa e, nessa situação, lidera a prática da tortura para encerrar a campanha terrorista.

Hoje, as doutrinas majoritárias brasileira (mesmo que pouco discutida no país) e, principalmente a americana, consideram a teoria do cenário da bomba-relógio (ticking bomb scenario theory) um exercício hipotético, feito in mente, que objetiva a obtenção, pelo Estado, de informações cruciais e específicas, por meio da tortura de suspeitos de saber sobre ou integrar planos de ataques terroristas, em benefício da solução de uma situação extrema, que coloca em risco a vida de um número indeterminado de pessoas. É uma técnica de consecução de informes, de caráter emergencial, que busca prevenir e combater atos terroristas imediatos, desativando o cenário da bomba-relógio.

Para melhor ilustrar, utilizemos o seguinte exemplo fictício: a polícia local recebe a informação de que há uma bomba-relógio plantada de imenso potencial destrutivo, na própria cidade, cuja única informação existente é a de que está fixada em ambiente público, porém sem exatidão, onde certamente colocará em risco grande parte da população inocente. Os grupos de inteligência que receberam a iminente ameaça conseguem localizar um dos envolvidos no atentado e o capturam com o intuito de obter referências acerca do explosivo, pois crêem que o mesmo tem notícias relevantes sobre o ato. Entretanto, quando conduzido perante as autoridades responsáveis pela investigação, o suspeito se recusa a fornecer os dados do paradeiro da bomba ou dos co-autores e partícipes. Diante da abstenção de cooperação com os investigadores, e notificados de que a bomba-relógio está ativada, com o cronômetro em regresso, e que perecerá diversas vidas, até o fim do tempo restante, suscita-se uma questão fascinante: é válido submeter o suspeito a práticas de tortura e outros atos desumanos a fim de arrancar, de modo coercitivo, indicações e explicações capazes de levar a equipe ao local da bomba prestes a explodir e desativá-la? Caberia, como sustenta alguns doutrinadores, a exclusão da antijuridicidade, caso os investigadores utilizassem de técnicas de tortura tão e somente nesta hipótese? 


\subsection{A QUESTÃO ÉTICA DIANTE DO CENÁRIO DA BOMBA- RELÓGIO}

Em artigo escrito pela Association for the Prevention of Torture, os autores estatuem que a situação da bomba-relógio age por meio da dominação das relações emocionais do público, criando um cenário de medo e raiva, deformando a realidade e criando simpatia para com o torturador e ódio em relação à vítima. ${ }^{15}$

É por isso que sua natureza dramática se tornou um dos maiores enredos de seriados e filmes de ação, justamente por criar um contexto, in mente, poderoso e preocupante aos olhos das organizações de direitos humanos, dos juristas e das autoridades militares. ${ }^{16}$

Qualquer que seja a oportunidade de transmissão da ideia, o efeito é sempre gerar dubiedade quanto à proibição absoluta da tortura. É fazer com que o público aceite uma exceção para a vedação. A partir daí, torna-se possível perceber que o problema tem pendências, além do jurídico, para o âmbito ético-moral, que gera fortes dissidências de opiniões entre especialistas e o coletivo.

É certo que, em muitos casos, não há solução real e humanamente possível, já que envolve matéria temporal, distinta de caso a caso. Mas, seria eticamente aceitável praticar atos desumanos para desvendar o cenário da bomba-relógio e, assim, salvar vidas, ou também é antiético deixar que milhares de pessoas morram? As possíveis soluções são as seguintes: torturar o suspeito não é ético e se torna injustificável, mas ele pode ser

\footnotetext{
${ }^{15} \mathrm{O}$ artigo "Whatever it takes: the politics of the man behind ' 24 "', escrito por Jane Mayer, em 2007, demonstra como o protagonista de um famoso seriado televisivo - "24 horas" age diante de situações de ticking bomb scenario. As temporadas da série descrevem, por exemplo, casos em que terroristas estão prestes a detonar bombas nucleares ou armas biológicas, capazes de aniquilar cidades. Frequentemente o herói se encontra diante de um difícil dilema: dar ao suspeito o devido processo legal, permitindo a continuidade da ação terrorista, ou ser torturado e obter certas vantagens. Por óbvio, escolhe a coerção, agindo com espancamentos e outros métodos que, quase sempre fazem com que os suspeitos divulguem segredos essenciais. O criador da série admitiu que se trata de uma situação que nunca, ou muito raramente, ocorre na vida real. Também analisa a obra francesa, mãe das representações da teoria, e concluiu que, examinando os registros históricos disponíveis, a história não tem base na realidade.

${ }^{16}$ Association for the Prevention of Torture. Defusing the Ticking Bomb Scenario: Why we must say No to torture, always. 2007. Disponível em: <http://www.apt.ch/content/files_res/tickingbombscenario.pdf>. Acessado em: 6 dezembro 2016.
} 
perdoado, ou, torturar o suspeito não é ético, mas nesse ponto é a "coisa correta a se fazer". ${ }^{17}$

Para melhor ilustrar a situação conflitante da ética com o cenário da bomba-relógio, o assessor jurídico da Anistia Internacional, Yuval Ginbar, em obra publicada em 2008, assevera que a ética é responsável por comparar as consequências das duas vias de ação disponíveis para ela, limitando-se ao futuro próximo e às pessoas imediatamente afetadas. Além disso, o autor nomeia três personagens (a autoridade, o suspeito e os civis inocentes), que participam de duas situações com produtos distintos, a saber ${ }^{18}$ :

a) A primeira situação é se a autoridade tortura o suspeito. A conclusão é de que aquele tem que passar pela dolorosa e, possivelmente traumática, experiência de lesionar gravemente outro ser humano que está a sua mercê;

b) A segunda situação é se a autoridade não tortura o suspeito. A consequência é a explosão da bomba, além de fazer com que aquele passe pela igualmente dolorosa e, possivelmente traumática, experiência de aprender sobre mortes e ferimentos entre os civis inocentes, bem como a dor de suas famílias, e sofrerá de culpa aguda por não ter salvado os cidadãos comuns quando podia. ${ }^{19}$

\subsection{PRESSUPOSTOS PARA A INCIDÊNCIA DA TEORIA}

A doutrina, aqui, consubstanciada nas explicações do professor e Promotor de Justiça Rogério Sanches Cunha, defende que só é possível

17 BBC London. The Scenario, BBC London. Disponível em: <http://www.bbc.co.uk/ethics/torture/ethics/tickingbomb_1.shtml>. Acessado em 6 dezembro 2016.

${ }^{18}$ Ethics (E) compares the consequences of the two avenues of action available to her. As noted earlier, she will limit herself to the immediate future and to those immediately affected, namely herself, Vicious (V) and the innocent civilians (IC), although she would probably go slightly beyond the latter, to include their families. This task is not contentious, nor is it particularly difficult. Ethics likely considerations are set in the table below:

IF E TORTURES V = E has to undergo the painful, possibly traumatic, experience of severely hurting another human being who is at her mercy.

${ }^{19}$ GINBAR, Yuval. Why not torture terrorists? Moral, Practical and Legal Aspects of the 'Ticking Bomb' Justification for Torture. New York: Oxford University Press, 2008. p. 36. 
discutir a teoria, e não necessariamente admiti-la, se estiverem presentes dez pressupostos, analisados a priori. ${ }^{20}$

A defesa também recai no sentido de que o proponente do cenário pode adaptar as premissas ou fazer manobras, que conduzem a exceção da proibição a níveis mais amplos que o original. São os seguintes enunciados:

1. É imperioso que haja um plano de ataque específico e determinado. Não há como cogitar a incidência dessa teoria diante de planos vagos, incertos ou indeterminados;

2. Deve ser um ataque cujo acontecimento é iminente, que irá ocorrer num prazo de tempo muito curto;

3. O ato terrorista matará, ou pelo menos colocará em perigo, um número indeterminado e expressivo de pessoas;

4. O suspeito sob custódia do Estado deve, necessariamente, estar envolvida, direta ou indiretamente, no ataque;

5. O suspeito in custodia deve ter informações relevantes e imprescindíveis que impedirão a conclusão do plano;

6. A tortura deve ser o ato hábil a obter a tempo informações para evitar o mal. Trata-se de um pressuposto revelador da utilidade do ato desumano;

7. Não pode existir outro meio potencialmente seguro, útil e eficaz para obter as informações a tempo. É o caráter de inevitabilidade da tortura; a ofensiva;

8. Não pode haver outra ação possível de ser tomada para impedir

9. A motivação do torturador deve ser apenas, e tão somente, conseguir as informações relevantes para o caso e com a pura intenção de salvar vidas, e nada mais; e

10. Deve ser uma situação isolada, que não se repetirá com frequência e não será tomada para qualquer tipo de caso.

Como ressaltado, há possibilidade de refutação das premissas, que, na opinião da Association for the Prevention of Torture, revela que o que está sendo sugerido não é uma exceção extraordinária, mas uma nova

20 O exemplo dado pelo professor foi proferido em vídeo. Disponível em: <https://www.youtube.com/watch?v=1NIHrd9h6_E\&t=1357s>. Acessado em 3 dezembro 2016. 
regra permitindo a tortura, o que nos faria retroceder aos tempos remotos das sociedades totalitárias.

Apesar de raras, as hipóteses de ticking time bomb cases solicitam precisão nas informações.

Sendo assim, quão iminente deve ser um ataque terrorista para justificar a tortura dos suspeitos? Deve ser contado em horas, dias ou meses? É extremamente improvável que os torturadores saibam, com perfeita exatidão, que a pessoa capturada é um dos responsáveis e tenha informações expressivas, quantas vidas correm perigo, se era possível realizar o resgate de outra forma. Ou então, o que ocorreria caso o suspeito conseguisse ludibriar as autoridades pelo tempo razoável para a ocorrência do atentado?

Nota-se que, partindo destes questionamentos e dúvidas, por constituir certa exceção a uma regra jurídica mundialmente celebrada, deveria ser dotada do mínimo de certeza.

Não há o que se falar de uma possível brecha da proibição da tortura sem ferir direitos fundamentais e os princípios da razoabilidade e da proporcionalidade.

\subsection{TEORIAS LEGITIMADORAS DA TORTURA NO CENÁRIO DA BOMBA-RELÓGIO}

A doutrina brasileira, com base nos ensinamentos da doutrinadora sul-rio-grandense Débora de Almeida, reproduzidos em explicação por Rogério Sanches Cunha ${ }^{21}$, admite quatro teorias que legitimam a tortura do suspeito em uma situação radical, fundadas tanto nos institutos penais relativos à exclusão da antijuridicidade, bem como no chamado "mandado de tortura".

A primeira corrente trabalha com a teoria da decisão racional, pela qual dois ou mais indivíduos possuem diversas opções, diante às quais uma escolha ou outra determinará respostas melhores ou piores, consubstanciando, também, o princípio do mal menor, iniciado por São Tomás de Aquino.

\footnotetext{
21 A listagem das teorias foi dada pelo professor, por meio de vídeo. Disponível em: $<$ https://www.youtube.com/watch?v=lNIHrd9h6_E\&t=1357s >. Acessado em 3 dezembro 2016.
} 
Lato sensu, esta orientação significa que, sendo iminentes males invitáveis, é mais acertado optar pelo menor, escolhendo-o a fim de evitar o maior. Posteriormente, é possível retirar outro sentido, restrito, de que o preceito significa que, quando todas ou individualmente as decisões são desfavoráveis e não há qualquer alternativa, deve-se priorizar a menos negativa.

Dessa forma, os adeptos invocam o estado de necessidade, que, em uma situação oscilante, pelo princípio referido do mal menor, a tortura se justificaria.

Essa corrente, nos dizeres de Rogério Sanches Cunha, tenta nos seduzir com exemplos exagerados e catastróficos, verbi gratia, a colocação em funcionamento de uma bomba atômica.

A segunda corrente, ao contrário da primeira, diz que a tortura se torna válida por ser um caso de legítima defesa de terceiros, já que não há qualquer violação dos direitos fundamentais do suspeito, pois, por haver criado o contexto da bomba-relógio, perdeu qualquer direito tutelado pelo Estado. A produção de um estado extremo de bomba-relógio deve ser entendida como um mal injusto, iminente, contra direito próprio e, principalmente, de outrem.

Em terceiro lugar, há quem defenda que o facere do Estado torturando o suspeito não constitui estado de necessidade, tampouco legítima defesa de terceiros. O que pode acontecer é aquele ser autorizado, por vias judiciais, a assim operar.

A importância e participação do Poder Judiciário, para essa corrente, estão na concessão do chamado "mandado de tortura", que pode ser provido por qualquer Juiz de Direito ou, ainda, pela própria autoridade em um Estado cujo ordenamento jurídico foi substituído por uma Lei Marcial, isto é, de cunho militar.

A ressalva feita pelos partidários dessa posição é que o torturador deve contar, no momento do ato, com a autorização, cumprindo os requisitos de expedição desta.

Em derradeiro, não constituindo uma quarta corrente, mas sim uma breve reformulação da anterior, há seguidores entendendo que, caso a autoridade torturadora não possua, o mandado no instante do feito, a tortura pode ocorrer da mesma maneira, devendo apenas obter uma ratificação judicial desta em momento posterior.

Hoje, se destaca nos Estados democráticos e sociais, que nem mesmo a situação hipotética da ticking bomb scenario justifica a tortura do 
suspeito. Prevalece como corrente majoritária o entendimento de que, se as práticas forem autorizadas, criará um modelo de clandestinidade para outras torturas, gerando, também, grande instabilidade no tocante aos direitos humanos. Rogério Sanches Cunha sustenta, ainda, que há um grande risco em manejar a tortura como instrumento institucional de combate ao terrorismo, onde não haverá um caso isolado, mas passará a ser a viga-mestra. 22

\section{CONSIDERAÇÕES FINAIS}

A prática diária do Direito permite concluir que seu maior fim é a consecução da justiça perante toda sociedade, empenhando-se para ir de encontro às alterações no meio social, tal como a necessidade de regular condutas que antes, em momentos e contextos distintos, não tinham qualquer respaldo na ordem jurídica, nacional ou internacional.

Exemplo disso é a tortura, que há muito foi admitida, e hoje, após diversos episódios responsáveis por ceifar a vida de milhares de cidadãos inocentes ao redor do mundo, fez com que o ordenamento jurídico como um todo caminhasse com olhares para um, ainda árduo, repúdio total.

Sabe-se que a atuação de grupos terroristas acontece desde muito tempo, porém, hoje, noticiam-se dias em que novas organizações de cunho terrorista, emergentes após os primeiros anos da chamada "Nova Ordem Mundial", colocam em prática planos de ação e, em poucos dias, ou até mesmo horas, faz milhares de vítimas. Cabe aqui lembrar alguns casos recentemente ocorridos, como o memorável episódio do ataque às Torres Gêmeas do World Trade Center, nos Estados Unidos; os ataques à casa de shows francesa Bataclan ou às estações de trem na Bélgica; as ofensivas realizadas pelos mais diversos grupos terroristas, vide Estado Islâmico (EIIL), Boko-Haram, Al-Qaeda, ETA, Farc, IRA, Hamas e outros.

O Brasil, nesse contexto, como aponta os principais doutrinadores que já escreveram sobre o tema, às pressas e com vistas aos eventos esportivos de alcance mundial que ocorreram no país, promulgou em 2016, a lei que tipifica o crime de terrorismo. Esse fato contribui para provar que convivemos com constantes ameaças, mas também que não devemos ceder

\footnotetext{
${ }^{22}$ Comentário feito pelo professor, por meio de vídeo. Disponível em: <https://www.youtube.com/watch?v=lNIHrd9h6_E\&t=1357s >. Acessado em 3 dezembro 2016.
} 
a elas, tampouco relativizar direitos fundamentais com o intuito de extingui-las. O caminho não é esse.

A Suprema Corte Americana, com o objetivo de barrar toda e qualquer ameaça que coloque em xeque a soberania e segurança nacional, chegou a afirmar, na voz do ex-ministro Justice Antonin Scalia, que a utilização de técnicas de interrogatório severas pode ser recepcionada pela Constituição do país.

É a partir de opiniões e teses como esta que se faz possível acomodar a proposta de uso de atos desumanos, isto é, a relativização do princípio proibitivo da tortura em casos extremos, para forçar a fala de um suspeito possuidor de informações relevantes sobre a localização de uma bomba-relógio prestes a explodir.

A tortura constitui procedimento de exclusão da liberdade de autodeterminação do ser humano, retirando seu direito de escolher livremente, de fazer algo ou não fazer, de não ter sua capacidade de resistência reduzida. São atos que afastam a dignidade humana como um todo, nos seus mais íntimos detalhes, e remontam um cenário arcaico, que, temporalmente, datam de trezentos anos atrás, e se tornam instrumento de alcance para apurar informações que, muitas vezes, podem nem mesmo serem verdadeiras.

A prática de qualquer ato que configure a tortura é totalmente vedado e repudiado, como demonstra o teor de diversos documentos internacionais de direitos humanos. Portanto, resta claro que a adoção de uma tese que relativize um preceito proibido de um crime repudiado por toda a comunidade global, representa grave afronta aos direitos da pessoa humana, além de ser totalmente desarrazoada a noção de que é plenamente possível limitar a tortura a casos que completem certo rol de pressupostos. Estes, em grande parte, ambíguos, vagos, impossibilitando conhecer, de imediato, as consequências que a prática acarretará e se, de fato, haverá informação útil para salvar outras vidas.

A história da humanidade mostra que, como outros institutos e ações, caso aceita a quebra da proibição absoluta, existem fortes tendências de que se torne instrumento institucionalizado de combate ao crime organizado e ao terrorismo. Apesar de quatro diferentes institutos buscarem legitimar a tortura, não há o que se falar, conforme o senso maior, em qualquer excludente de antijuridicidade, justamente pelo fato de ser absoluta, não considerando qualquer exceção. Ainda, as excludentes são concessões do Estado ao particular para que este, infringindo um tipo penal para 
garantir a defesa de outro bem jurídico igualmente tutelado, não incorra em delito. Ao Estado cabe o dever de proteção dos bens jurídicos de maior valor dos cidadãos, podendo recair em desrespeito a paradigma constitucional do Estado Democrático de Direito, não havendo, portanto, qualquer dever de torturar.

Os seres humanos, perseguindo quais objetivos, devem manter a humanidade em todos os momentos. A comunidade internacional deve fazer tudo o que for humanamente possível para salvar as vidas em risco de perecimento, porém, sem perder a própria vida na persecução desse fim. Isso significa nunca rebaixar a dignidade de outro ser humano, em qualquer circunstância, seja por atos degradantes em geral, ou, em específico, pela tortura.

Resta concluir que é completamente incabível, nos termos discutidos, uma exceção ad hoc de um princípio constitucionalmente consagrado, em diversos documentos e tratados internacionais. Os parâmetros estabelecidos para o bom funcionamento do Estado Democrático de Direito afastaram, desde logo, esse modelo de ato, e, por isso, seriam incalculáveis as decorrências desse retrocesso social. A pessoa é um fim em si mesmo, e seu desprezo à condição de meio para concluir outros objetivos, sejam estes genuínos ou perniciosos, apenas reitera que a coisificação da pessoa humana jamais deve ser admitida.

\section{REFERÊNCIAS BIBLIOGRÁFICAS}

ALEXY, Robert. Teoria dos Direitos Fundamentais. 5.ed. São Paulo: Malheiros, 2008.

ASSOCIATION for the Prevention of Torture. Defusing the Ticking Bomb Scenario: Why we must say No to torture, always. 2007. Disponível em: <http://www.apt.ch/content/files_res/tickingbombscenario.pdf>. Acessado em: 6 dezembro 2016.

BBC London. The Scenario, BBC London. Disponível em: http://www.bbc.co.uk/ethics/torture/ethics/tickingbomb_1.shtml. Acessado em 6 dezembro 2016.

CALLEGARI, André Luís. A exclusão da ilicitude do torturador de terceiro possuidor de informação num cenário de tickin time bomb. Disponível em: $\langle$ http://ebooks.pucrs.br/edipucrs/anais/cienciascriminais/III/5.pdf $>$. Acessado em: 06 dezembro 2016.

COMPARATO, Fábio Konder. A afirmação histórica dos direitos humanos. 3.ed. São Paulo: Saraiva, 2003. 
CUNHA: Rogério Sanches. Grupo de estudos: ticking bomb scenario theory. O exemplo dado pelo professor foi proferido em vídeo. Disponível em: <https://www.youtube.com/watch?v=1NIHrd9h6_E\&t=1357s >. Acessado em 3 dezembro 2016.

GINBAR, Yuval. Why not torture terrorists? Moral, Practical and Legal Aspects of the 'Ticking Bomb' Justification for Torture. New York: Oxford University Press, 2008.

GRECO, Luís. As regras por trás da exceção - Reflexões sobre a tortura nos chamados "casos de bomba-relógio". Revista Jurídica v. 23, n. 7 (2009). Disponível em: <http://revista.unicuritiba.edu.br/index.php/RevJur/article/view/95>. Acessado em: 10 dezembro 2016.

HENKIN, Louis. The rights of man today. New York: Columbia University Press, 1988.

KANT, Immanuel. Metafísica dos Costumes. 1.ed.Lisboa: Edições 70 LDA, 2007.

MAYER, Jane. Whatever it takes: the politics of the man behind '24'. The New Yorker, 2007. Acessado em: 10 dezembro 2016.

RAMOS, André de Carvalho. Teoria geral dos direitos humanos na ordem internacional. 2.ed.São Paulo: Saraiva, 2012.

RAMOS, André de Carvalho. Curso de direitos humanos. 3.ed.São Paulo: Saraiva, 2016.

SILVA, José Afonso da. Curso de Direito Constitucional Positivo. São Paulo: Malheiros, 2008.

SILVA DIAS, Augusto. Torturando o inimigo ou libertando da garrafa o génio do mal? Sobre a tortura em tempos de terror. Disponível em: < www.amprs.org.br/arquivos/revista_artigo/arquivo_1342125881.pdf>. Acessado em: 06 dezembro 2016. 